\title{
PHYSICAL MODEL ON WAVE DISSIPATION EFFECT OF PERFORATED CAISSON
}

JIANG Yunpeng, CHEN Hanbao, GE Longzai

Tianjin Research Institute for Water Transport Engineering, Key Laboratory of Engineering Sediment of Ministry of Transport, Tianjin 300456, China
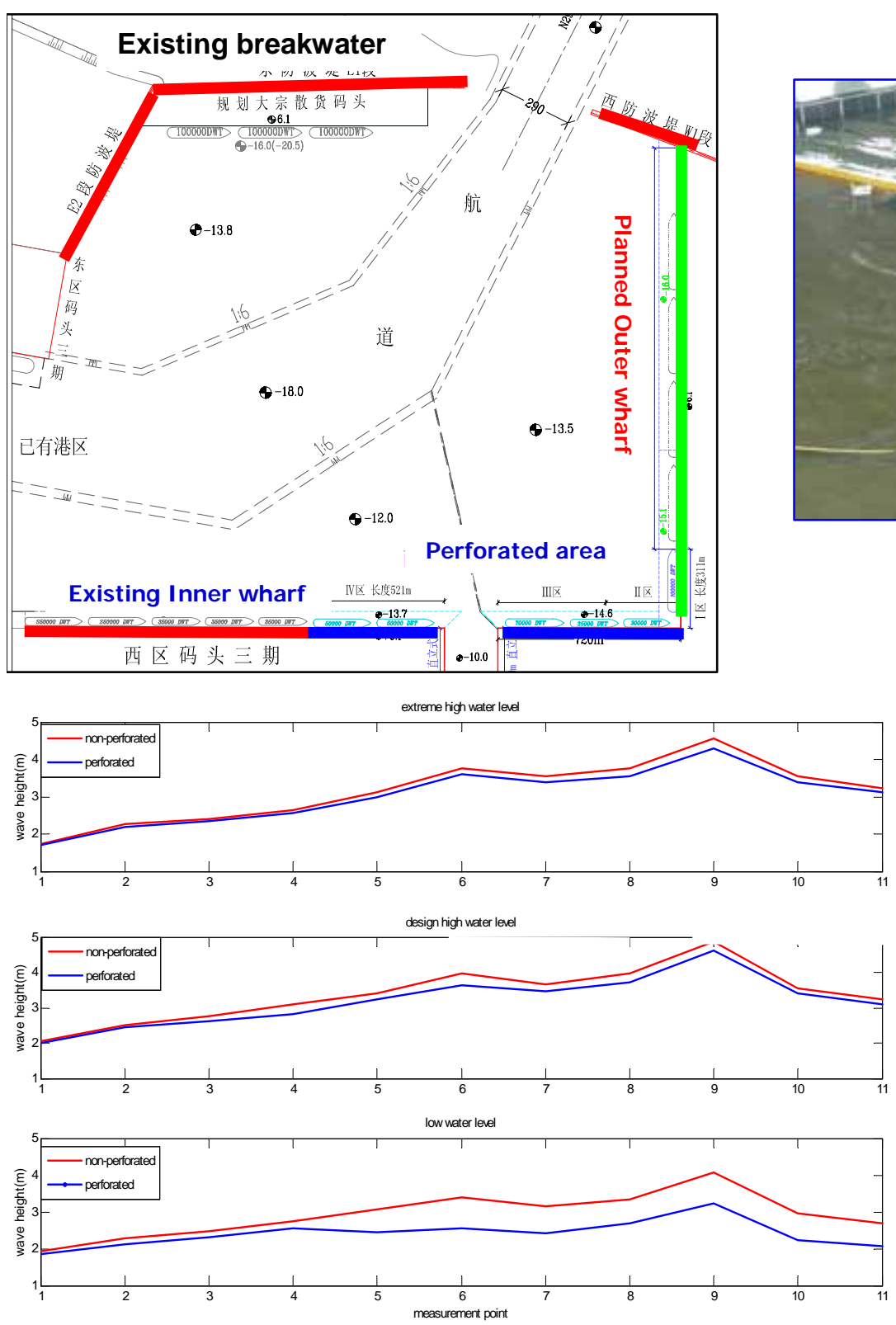

Wave height of cases of non-perforated caisson and perforated caisson

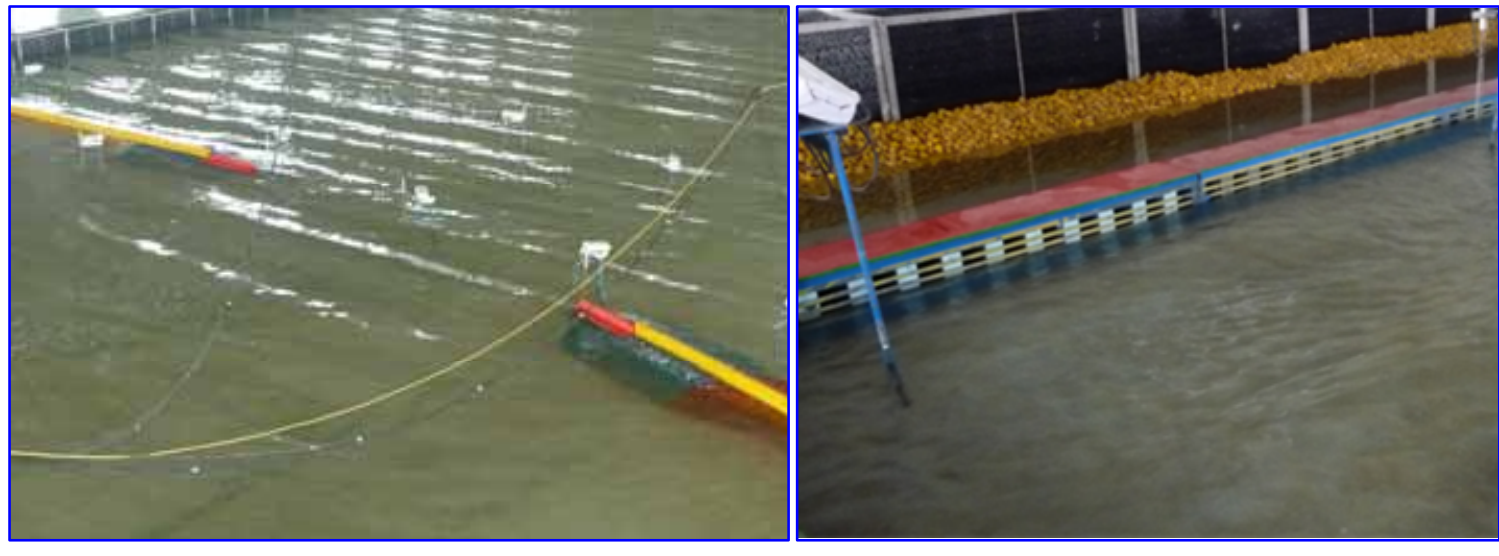

Wave height reduction percent relative to non-perforated caisson

\begin{tabular}{|c|c|c|c|c|}
\hline \multirow{2}{*}{ Cases } & \multicolumn{2}{|c|}{ E } & \multicolumn{2}{c|}{ ENE } \\
\cline { 2 - 5 } & H.W.L. & L.W.L. & H.W.L. & L.W.L. \\
\hline \multirow{2}{*}{ I、II area } & $5.3 \%$ & $22.7 \%$ & $4.8 \%$ & $26.4 \%$ \\
\hline III area & $5.8 \%$ & $19.8 \%$ & $3.2 \%$ & $21.0 \%$ \\
\hline IV area & $4.3 \%$ & $23.8 \%$ & $6.1 \%$ & $27.2 \%$ \\
\hline
\end{tabular}

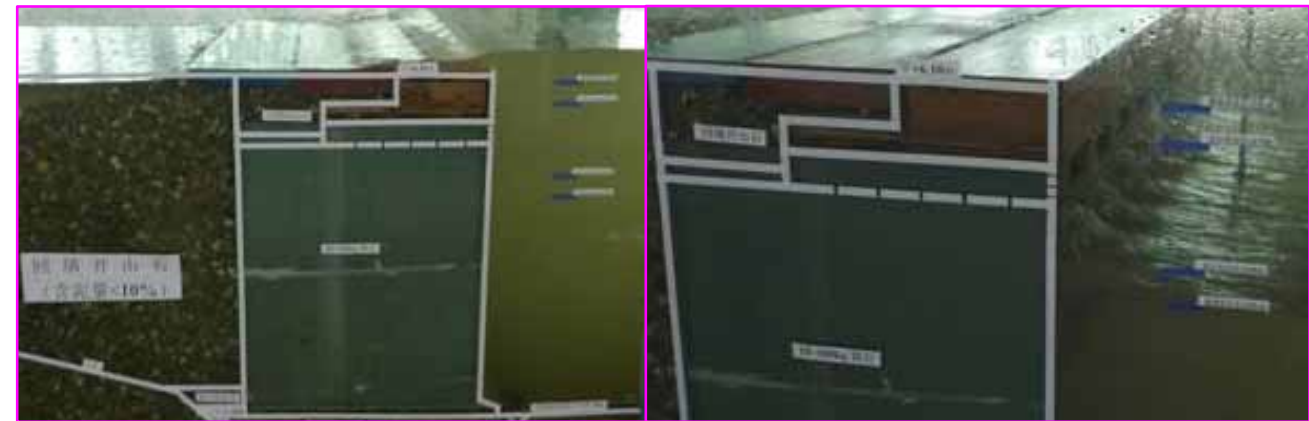

